\title{
Turismo e meio ambiente: inventário dos temas e autores brasileiros
}

\section{Tourism and the environment: inventory of themes and Brazilian authors}

\author{
Alex Sandro Barbosa (BARBOSA, A. S.)*, \\ Mario Marcos Lopes (LOPES, M. M.) ${ }^{* *} \mathrm{e}$ \\ Denilson Teixeira (TEIXEIRA, D.)***
}

\begin{abstract}
RESUMO - A presente pesquisa teve como objetivo inventariar os temas e autores na área de turismo e meio ambiente, suas pesquisas e lacunas existentes neste campo de pesquisa (do ano 1987 para o ano 2006). O inventário é formado por 63 teses e está organizado e analisado sob os seguintes aspectos: caracterização geral, análise disciplinar, temática, autores e procedimentos metodológicos. O inventário dos temas e autores na área de turismo e meio ambiente foi o início das pesquisas que objetivaram analisar a produção acadêmica nessa área. Os dados revelaram que o interesse pela pesquisa estava crescendo nas Instituições de Ensino Superior (IES) pelo Brasil e que diversas áreas do conhecimento com seus variados procedimentos metodológicos estavam pesquisando a relação turismo e meio ambiente, tornando-a, assim, uma área particular de estudo.
\end{abstract}

Palavras-chave: Turismo; Meio ambiente; Banco de teses - CAPES.

ABSTRACT - This research aimed to inventory the themes and authors in environment and Ttourism area, the research gaps in this research field (from 1987 to 2006). The inventory consists in 63 theses and it is organized and analyzed from the following aspects: general characterization, subject analysis, theme, authors and methodological

\footnotetext{
* Formação: Graduação em Turismo pela Universidade Estadual do Oeste do Paraná (UNIOESTE) e Mestrado em Desenvolvimento Regional e Meio Ambiente pelo Centro Universitário de Araraquara (UNIARA). Professor efetivo da Universidade do Estado de Mato Grosso (UNEMAT). Endereço físico para correspondência: Universidade do Estado de Mato Grosso, Departamento de Turismo. BR 158 Km 655. CEP 78690-000 - Nova Xavantina/MT - Brasil. E-mail: turismo.nxa@unemat.br

** Formação: Graduação em Ciências Biológicas pelo Centro Universitário Barão de Mauá, Aperfeiçoamento em Educação Ambiental pela Universidade Federal de São João Del-Rei (UFSJ), Especialização em Didática e Tendências Pedagógicas e em Gestão Escolar pela Faculdade de Educação São Luís (FELS) e Mestrado em Desenvolvimento Regional e Meio Ambiente do Centro Universitário de Araraquara (UNIARA). Professor-tutor da Universidade Federal de São Paulo (UNIFESP). Professortutor e orientador de TCC nos Cursos de Especialização na Modalidade a Distância da Faculdade de Educação São Luís de Jaboticabal (FELS) e do Centro Universitário Barão de Mauá, Ribeirão Preto/SP. Docente na disciplina de Biologia (Secretaria de Estado da Educação). Endereço físico para correspondência: Centro Universitário de Araraquara - Programa de Mestrado em Desenvolvimento Regional e Meio Ambiente. Rua Carlos Gomes, 1338 (Centro). CEP 14801-340 - Araraquara/SP - Brasil. E-mail: mmarlopes@ig.com.br

**** Formação: Graduação (licenciatura e bacharelado) em Ciências Biológicas pela Universidade Federal de São Carlos (UFSCar), Especialização em Geoprocessamento na mesma instituição, Mestrado e Doutorado em Ciências da Engenharia Ambiental pela Universidade de São Paulo (EESC/USP). Professor adjunto da Universidade Federal de Goiás (UFG) e membro do corpo de editores da Revista UNIARA. Endereço físico para correspondência: Universidade Federal de Goiás, Escola de Engenharia Civil. Praça Universitária 1488, Qd. 86, Setor Leste Universitário. CEP 74605-220- Goiânia/GO - Brasil. E-mail: dteixeira@ufg.br
} 
procedures. The inventory of topics and authors in Tourism and the environment was the beginning of the research that aimed to analyze the academic production in these areas. The data revealed that the interest in research has increased in Education Institutions (EI) in Brazil and that several areas of knowledge with their various methodological procedures have been researching the relationship between tourism and environment, thus turning it in a particular area of study.

Key words: Tourism; environment; Bank of theses - CAPES. 


\section{INTRODUÇÃO}

A dimensão econômica do turismo, mesmo que atinja grandes estruturas e gere cifras consideráveis, não pode ser encarada como a única questão do desenvolvimento da atividade.

Nos primeiros estudos sobre os impactos do turismo como atividade econômica, desenvolvidos no contexto capitalista, se entendiam que esses impactos seriam facilmente quantificados e os benefícios gerados pela renda arrecadada supririam qualquer e eventual consequência negativa (MAMEDE, 2003).

Uma nova etapa de discussão contrapõe a superestimação da dimensão econômica do turismo em relação a questões ambientais.

A partir das décadas de 1960 e 1970, com os movimentos ambientalistas, as questões ligadas ao desenvolvimento começam a ser delineadas como consequência dos desequilíbrios ambientais e de seus efeitos (RODRIGUES, 2003). Em 1972, na Conferência de Estocolmo ${ }^{1}$ foram estabelecidos princípios para a solução dos problemas ambientais, seguida pela Rio- $92^{2}$ e pela Conferência de Johannesburgo ${ }^{3}$, em 2002. Nesse contexto, surgem discussões sobre novos tipos de turismo de menor impacto sobre o meio ambiente e nas comunidades anfitriãs (LIMA, 2000 ${ }^{4}$ apud RODRIGUES, 2003).

Associada a essa ideia e pela busca de lazer em áreas naturais como um refúgio dos grandes centros urbanos, a década de 1990 foi marcada pela consolidação teórica

\footnotetext{
${ }^{1}$ A Conferência das Nações Unidas para o Meio Ambiente Humano, conhecida como Conferência de Estocolmo, realizada em 1972 em Estocolmo, na Suécia, foi a primeira Conferência global voltada para o meio ambiente, e como tal é considerada um marco histórico político internacional, decisivo para o surgimento de políticas de gerenciamento ambiental, direcionando a atenção das nações para as questões ambientais (PASSOS, 2009, p. 1).
}

2 Rio-92 também conhecida como Conferência das Nações Unidas sobre Meio Ambiente e Desenvolvimento, reafirmou a Declaração da Conferência das Nações Unidas sobre o Meio Ambiente Humano, adotada em Estocolmo em 16 de junho de 1972, e buscou avançar a partir dela, com o objetivo de estabelecer uma nova e justa parceria global mediante a criação de novos níveis de cooperação entre os Estados, os setores-chaves da sociedade e os indivíduos, trabalhando com vistas à conclusão de acordos internacionais que respeitem os interesses de todos e protejam a integridade do sistema global de meio ambiente e desenvolvimento, reconhecendo a natureza integral e interdependente da Terra (ONU, 2015).

${ }^{3}$ O objetivo principal da Conferência seria rever as metas propostas pela Agenda 21 e direcionar as realizações às áreas que requerem um esforço adicional para sua implementação, assim como refletir sobre outros acordos e tratados na Rio-92 (SEQUINEL, 2002).

${ }^{4}$ LIMA, M. L. C. (Eco)turismo em Unidades de Conservação. In: RODRIGUES, A. B. (Org.) Ecoturismo no Brasil: possibilidades e limites. São Paulo: Contexto, 2000. p. 71-87. 
dos conceitos relacionados à questão ambiental e à sustentabilidade, passando assim a ser uma meta para os diferentes segmentos da sociedade (BARBOSA, 2008).

$\mathrm{Na}$ área acadêmica, o tema turismo e meio ambiente, apesar de amplamente documentado, vinha sendo objeto de estudo de vários autores, como Ruschmann (2001), Rodrigues (2000), Swarbrooke (2000), Lemos (2001), Pinto (2001), Ferretti (2002), Pires (2002), Dias (2003), Queiroz (2006), além dos trabalhos publicados por Santos, Possamai e Marinho (2009), em que se abordam especificamente as teses de doutorado produzidas no Brasil entre 2005 e 2007, cadastradas no portal da CAPES, e de Momm e Santos (2010), em que focalizam o campo do estudo do turismo no Brasil no período de 2000 a 2006, apresentando os indícios de sua institucionalização, entre outros.

O turismo, com suas implicações socioeconômicas e ambientais, é uma atividade que requer grandes investimentos, inclusive em planejamento, para que o processo de degradação dos recursos naturais associados aos destinos turísticos seja mitigado (BARBOSA, 2008).

Assim, num planejamento em busca da melhor relação turismo e meio ambiente deve ter como objetivo principal alcançar a sustentabilidade da atividade econômica, tendo em vista a necessidade do envolvimento dos diferentes atores sociais como uma de suas premissas (BARBOSA, 2008). Este é, indubitavelmente, um importante ponto a ser discutido no contexto das ações, práticas e interações que envolvem os atores comprometidos.

Cabe destacar a importância de se observar que as propostas e questões ligadas ao desenvolvimento sustentável do turismo vão além da dimensão ecológica, pois compreendem também a melhorias das condições econômicas e sociais das populações locais (SILVEIRA, 1997).

Nesse contexto, tanto o conceito de "desenvolvimento sustentável do turismo" quanto o de "consumo responsável do turismo" são vistos como respostas que determinam o grau de solidez para que se favoreça um melhor planejamento e gerenciamento dessa atividade (MAMEDE, 2003).

Segundo Vilas Boas e Dias (2010), o desenvolvimento sustentável do turismo está baseado num equilíbrio harmônico entre três dimensões: a ambiental, a econômica e a sociocultural. Do ponto de vista ambiental e econômico, a participação da comunidade é importante para evitar que os recursos sejam destruídos e ainda para que 
o investimento feito não seja perdido, e do ponto de vista moral, deve-se controlar o seu próprio destino em vez de submeter-se a interesses externos.

A complexidade que envolve a atividade turística, seja em âmbito econômico, ambiental e/ou social, tendo como fundo o desenvolvimento sustentável, pode ser analisada e contextualizada pelo estudo da produção acadêmica inerente.

Assim, dada a importância dessas informações, considerou-se serem necessárias a sistematização documental desses trabalhos e a divulgação do conhecimento produzido junto a pesquisadores e estudiosos da área. Nesse contexto, o objetivo geral do presente estudo foi o de inventariar os temas e autores na área em questão, suas pesquisas e lacunas existentes nessa área de conhecimento.

Na presente pesquisa se teve como objetivo identificar e caracterizar os trabalhos de doutorado defendidos no Brasil de 1987 a 2006, nos quais a temática turismo e meio ambiente tivesse sido o objeto de estudo e, a partir dessa base de dados, analisar particularmente a produção dos principais autores, buscando, também, identificar possíveis lacunas existentes nesse campo de pesquisa.

A escolha desse intervalo de pesquisa se deve a intensificação de trabalhos neste período, necessitando de uma investigação sobre as diversas dimensões e objeto de estudo, preenchendo uma lacuna bibliográfica no estado da arte da pesquisa em turismo e meio ambiente, conforme aponta Barbosa (2008).

Cabe destacar que para a pesquisa se teve como antecedentes os trabalhos de Rejowski (1993 e 1995), que examinaram a produção do conhecimento científico na área de turismo, por meio da configuração e sistematização documental da pesquisa acadêmica em nível de pós-graduação Stricto Sensu no Brasil, no período entre 1970 e 1995.

Por fim, os resultados apresentados neste artigo são fruto de uma investigação elaborada para o Programa de Mestrado em Desenvolvimento Regional e Meio Ambiente do Centro Universitário de Araraquara (São Paulo), cumprindo com o objetivo de consolidar seu papel como centro produtor de pesquisa e de conhecimento voltado à discussão interdisciplinar e contextual do processo de desenvolvimento regional frente às questões ambientais. 


\section{PROCEDIMENTOS METODOLÓGICOS}

O banco de dados utilizado para a pesquisa foi o Portal de Teses e Dissertações da Coordenadoria de Aperfeiçoamento de Ensino Superior - CAPES (2006) ${ }^{5}$, além de consultas diretas à Coordenação de Acesso à Informação Científica e Tecnológica, órgão responsável pela alimentação do portal, bem como da divulgação das publicações científicas.

O universo de estudo desta pesquisa foi composto por 63 teses; nessa amostragem, realizada no Portal CAPES, se adotou os seguintes critérios: teses defendidas em Instituições de Ensino Superior no Brasil - IES de 1987 a 2006, nas quais a temática principal, presente nos resumos, tratava de turismo e meio ambiente de forma objetiva.

Para análise mais detalhada dos temas, autores e procedimentos metodológicos, fez-se necessária a busca pelas teses na íntegra.

Adjacente à identificação e seleção das teses, os seguintes dados foram registrados em uma ficha catalográfica adaptada do modelo estabelecido por Rejowski (1993):

a) caracterização geral (aspectos externos, independentes de conteúdo), ano, IES, cidade, Unidade da Federação - UF, região brasileira, programa de pós-graduação, área de concentração na CAPES e órgão financiador; b) análise disciplinar: área do conhecimento (estudo); c) análise temática: assuntos classificados, palavras-chave e tema de estudo; d) análise dos autores: perfil, período de graduação, curso de graduação, orientador, banca examinadora e referências bibliográficas; análise preliminar dos procedimentos metodológicos: aspectos quantitativos e qualitativos.

Os dados coletados foram organizados formando uma base de dados; o software utilizado foi o Access (Licença Uniara).

\footnotetext{
${ }^{5}<$ http://bancodeteses.capes.gov.br/>.
} 


\section{RESULTADOS E DISCUSSÃO}

Os resultados obtidos por meio da pesquisa foram organizados e analisados sob os seguintes aspectos: caracterização geral, análise disciplinar, temática, autores e procedimentos metodológicos.

\subsection{CARACTERIZAÇÃO GERAL}

O inventário dos temas e autores na área de turismo e meio ambiente está baseado em 63 teses de doutorado, disponíveis no banco de teses da CAPES; o período analisado, conforme detalhado no procedimento metodológico, foi de 1987 a 2006. Entretanto, a produção científica acerca do tema em discussão iniciou-se no ano de 1993, com uma tese de doutorado do autor Armando Garms, defendida na Universidade de São Paulo (USP) no programa de pós-graduação em Geografia Humana.

Observou-se que praticamente a maior quantidade (56) da produção acadêmica se concentrou entre 2000 a 2006. O auge na produção das teses se deu em 2002, com 14 trabalhos defendidos. A evolução da produção das pesquisas no período estudado está apresentada na Figura 1.

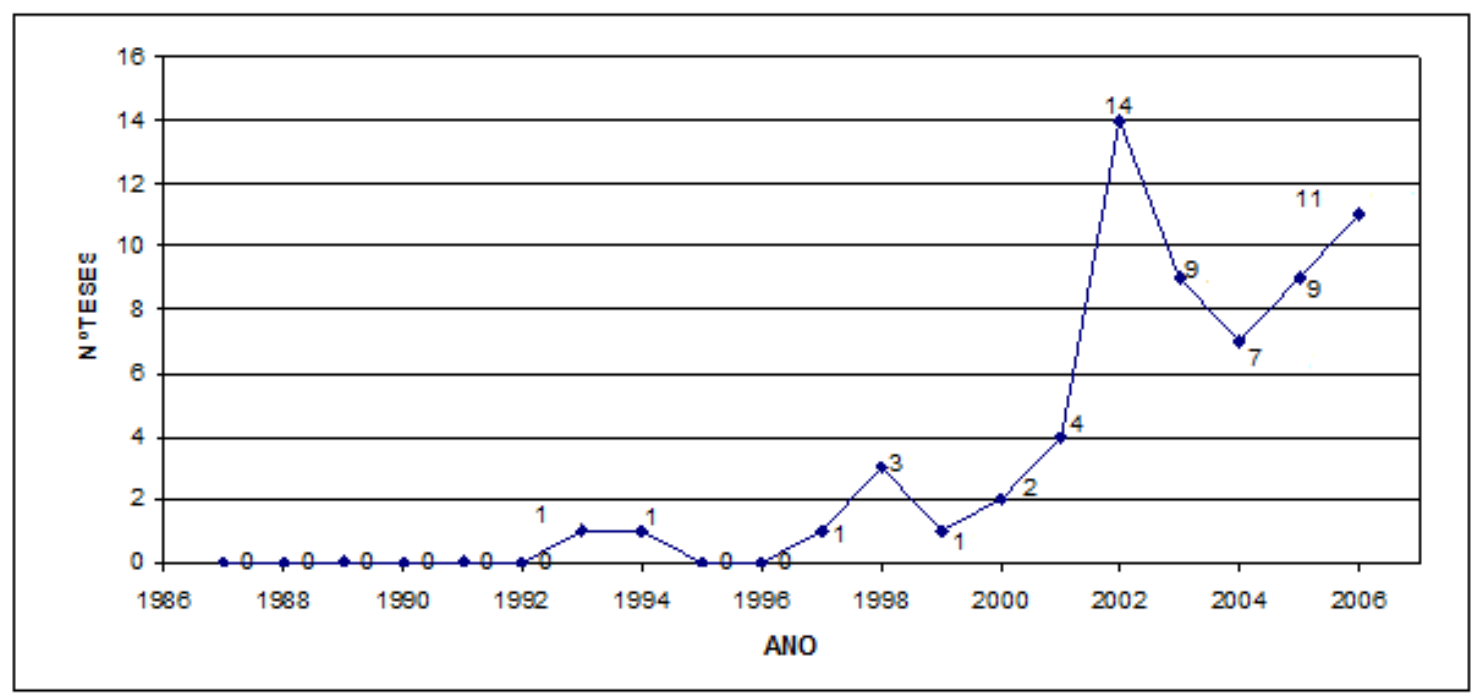

FIGURA 1 - EVOLUÇÃO DA PRODUÇÃO DAS TESES NO PERÍODO DE 1987 A 2006. Fonte: Pesquisa de gabinete, 2008.

Em uma análise contextual, identificou-se que 43 pesquisadores se formaram entre os anos 1970 e 1980. Esse foi um período de intensa discussão sobre as questões 
ambientais - conferências, reuniões, relatórios que alertaram o mundo a respeito da importância das questões ambientais ${ }^{6}$. Paralelo a esse momento, as atividades alinhadas ao turismo passam a ter os efeitos da "massificação" da atividade econômica, com o desenvolvimento da aviação comercial iniciada na década 1960; como consequência vieram os resultados prejudiciais ao meio ambiente, debatidos em eventos promovidos pela Organização Mundial de Turismo - OMT e Organização das Nações Unidas para a Educação, a Ciência e a Cultura - UNESCO.

Quando da caracterização das IES nas quais as teses foram elaboradas se verificou serem, em sua maioria, instituições públicas (61 produções), sendo uma privada, responsável por duas teses, confirmando a tendência geral de que a maior parte da produção científica brasileira se situava nas universidades públicas.

$\mathrm{Na}$ análise do número de teses por IES, destacou-se a Universidade de São Paulo (USP), onde quase metade das 63 teses foi elaborada a partir dos seus programas de pós-graduação. O número de teses por instituição está representado na Figura 2.

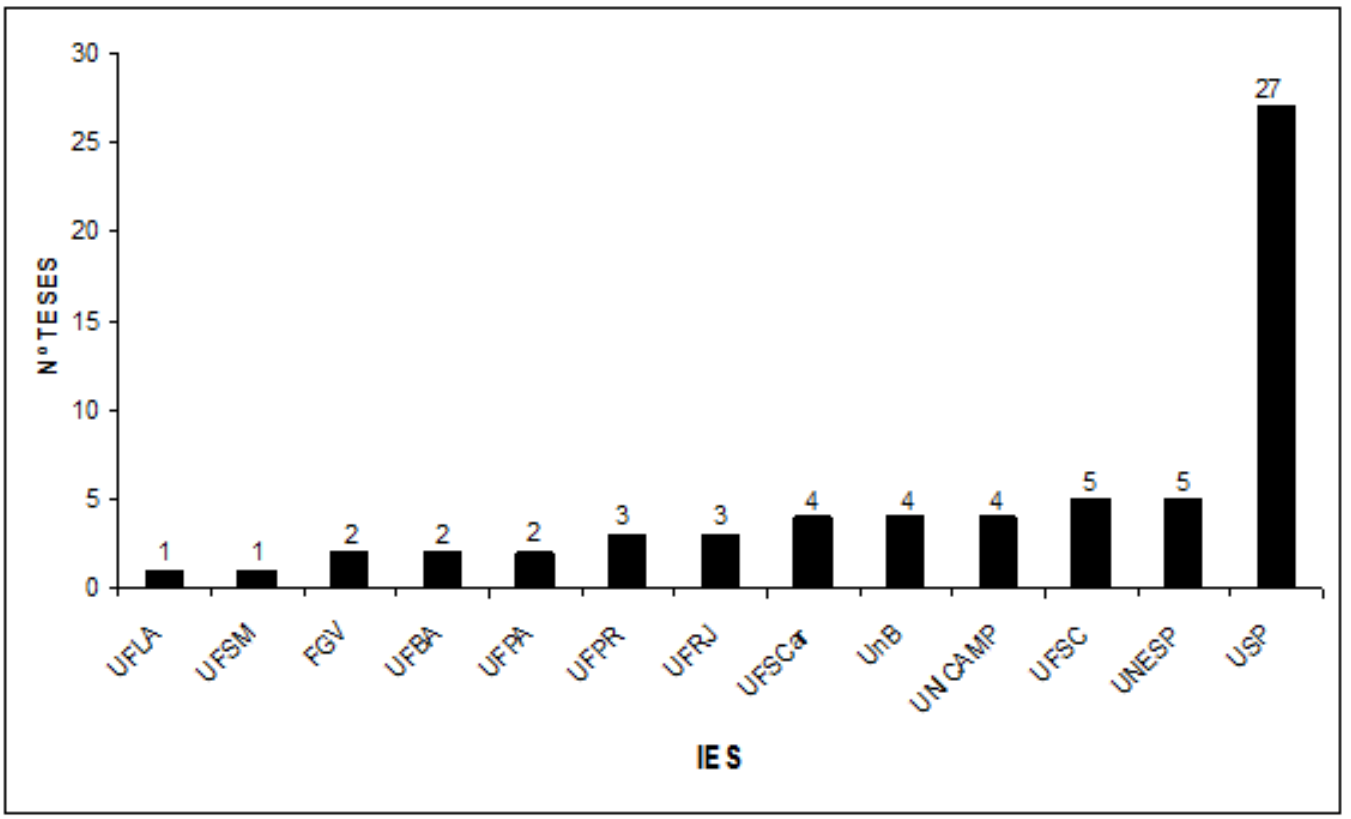

FIGURA 2 - GRÁFICO CRESCENTE EVIDENCIANDO A QUANTIDADE DE TESES DEFENDIDAS NAS IES ENTRE 1987 E 2006.

Fonte: Pesquisa de gabinete, 2008.

\footnotetext{
${ }^{6} 1972$ - Publicação do Relatório "Os Limites do Crescimento" - Clube de Roma; 1972 - Conferência de Estocolmo - Discussão do Desenvolvimento e Ambiente, Conceito de Ecodesenvolvimento. Recomendação 96 Educação e Meio Ambiente 1973 Registro Mundial de Programas em Educação Ambiental - USA; 1975 - Congresso de Belgrado - Carta de Belgrado estabelece as metas e princípios da Educação Ambiental; 1977 - Conferência de Tbilisi - Geórgia, estabelece os princípios orientadores da EA e remarca seu caráter interdisciplinar, critico, ético e transformador. (Cf. <http://www.mma.gov.br/educacao-ambiental/politica-de-educacao-ambiental/historico-mundial>.).
} 


\section{Legenda:}

UFLA = Universidade

Federal de Lavras

UFSM = Universidade

Federal de Santa Maria

FGV = Fundação Getúlio

Vargas (SP)

UFBA = Universidade

Federal da Bahia

UFPA = Universidade

Federal do Pará
UFPR $=$ Universidade

Federal do Paraná

UFRJ = Universidade

Federal do Rio de Janeiro

UFSCar = Universidade

Federal de São Carlos

UnB = Universidade de

Brasília

UNICAMP = Universidade

Estadual de Campinas
UFSC $=$ Universidade

Federal de Santa Catarina

UNESP = Universidade

Estadual Paulista

USP $=$ Universidade de São

Paulo

Pode-se afirmar que o grande número de teses na área de turismo e meio ambiente apresentado pela USP pode ser entendido, primeiro, pela concentração de especialistas em turismo, como os doutores Mário Carlos Beni, Miriam Rejowski, Doris Van de Meene Ruschmann, dentre outros além do pioneirismo na criação do curso de Turismo na Escola de Comunicações e Artes, no ano de 1973 (HALLAL, et. al, 2010). A USP, fundada em 1934, é a maior instituição de ensino superior e de pesquisa do Brasil e a terceira da América Latina (SCHMIDT et. al, 2010).

Esclareça-se que as 63 teses analisadas pertencem a 18 áreas distintas, determinadas pela CAPES, com destaque para a Geografia, com 16 teses, superando as demais áreas, como a Interdisciplinar, com 9 trabalhos, a Comunicação, com 6 pesquisas, e a Recursos Florestais/Engenharia Florestal, a Engenharia Sanitária, a Ecologia e a Arquitetura e Urbanismo, com 4 teses cada uma, conforme Figura 3.

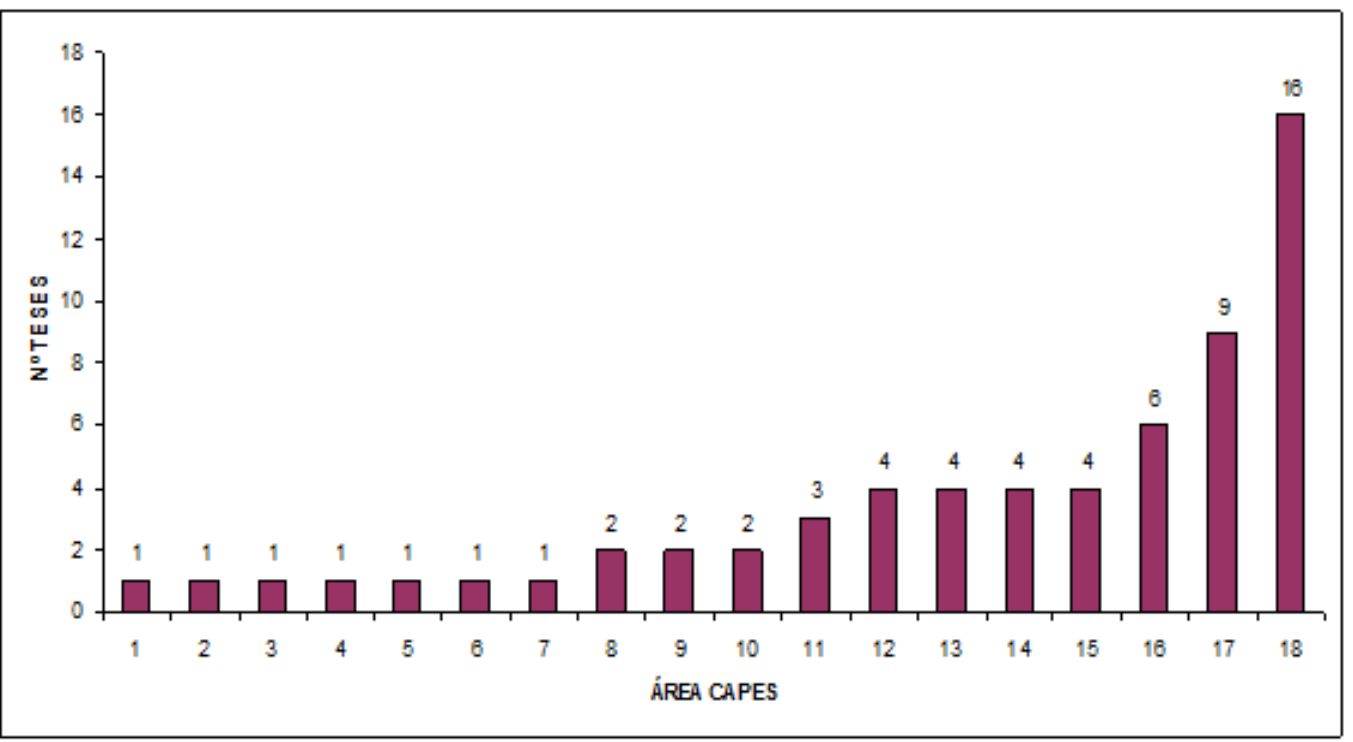

FIGURA 3 - GRÁFICO CRESCENTE REPRESENTANDO A QUANTIDADE E O PERCENTUAL DE TESES SEGUNDO A ÁREA DETERMINADA PELA CAPES

Fonte: Pesquisa de gabinete, 2008. 


\section{Legenda:}

$1=$ Agronomia

$2=$ Antropologia

3 = Economia

4 = Educação

$5=$ Engenharia Civil

$6=$ Geociências

7 = História

\author{
$8=$ Administração \\ 9 = Engenharia Agrícola \\ $10=$ Saúde Coletiva \\ $11=$ Sociologia \\ $12=$ Arquitetura e \\ Urbanismo \\ $13=$ Ecologia
}

\author{
$14=$ Engenharia Sanitária \\ $15=$ Recursos Florestais \\ Engenharia Florestal \\ 16 = Comunicação \\ $17=$ Interdisciplinar \\ $18=$ Geografia
}

\subsection{ANÁLISE TEMÁTICA}

Foram cadastradas 114 diferentes palavras-chave, citadas nas teses estudadas. A palavra-chave mais utilizada pelos autores foi Turismo, referida 25 vezes $(13,5 \%)$, seguida de Ecoturismo, com 20 vezes (10,8\%), Sustentabilidade, Políticas Públicas e Meio Ambiente, com 5 aparições cada uma (2,7\%). Turismo Sustentável, Turismo e Meio Ambiente e Turismo de Aventura tiveram menos de 4 citações cada. Apesar do grande número de palavras-chave citadas, foi possível agrupá-las em 7 temas: Administração, Desenvolvimento, Meio Ambiente, Política, Território, Turismo e Geral (Quadro 1).

\begin{tabular}{|l|l|}
\hline \multicolumn{1}{|c|}{ TEMA } & \multicolumn{1}{c|}{ PALAVRAS-CHAVE } \\
\hline Administração & $\begin{array}{l}\text { Corporação, Modelo de Gestão, Planejamento Ambiental, Planejamento e Gestão, } \\
\text { Planejamento Regional. }\end{array}$ \\
\hline Desenvolvimento & $\begin{array}{l}\text { Desenvolvimento Local, Desenvolvimento Local e Regional, Desenvolvimento } \\
\text { Sustentável, Desenvolvimento Turístico. }\end{array}$ \\
\hline Meio Ambiente & $\begin{array}{l}\text { Ambientalismo, APA, Área de Preservação, Áreas Protegidas, Conservação da } \\
\text { Biodiversidade, Conservação da Natureza, Crise Energética, Ecologia, Ecologia de } \\
\text { Macrofauna Bentônica, Ecologia Urbana, Energia Consumo, Engenharia Florestal, } \\
\text { Flora de Canela, Garimpo, Gestão Ambiental, Impacto Ambiental, Impactos } \\
\text { Ambientais, Lixo, Manejo Florestal, Parque, Poluição, Proteção Ambiental, } \\
\text { Recursos Naturais, Reserva Biológica, RPPN, Saneamento Básico, Sociologia } \\
\text { Ambiental, Sustentabilidade, Zoneamento Ecológico. }\end{array}$ \\
\hline Política & $\begin{array}{l}\text { Patrimônio Público, Política Ambiental, Políticas de Ordenamento Territorial, } \\
\text { Políticas Públicas. }\end{array}$ \\
\hline Território & $\begin{array}{l}\text { Paisagem, SIG, Solos, Terra, Território, Transformação da Paisagem, Amazônia, } \\
\text { Amazônicas, Bertioga, Bonito - MS, Brotas, Chapada, Estado, Itaipu, Itatins, } \\
\text { Jureia, Lapinha, Municípios do PRODETUR - RN, Pantanal, Paraná, Picinguaba, } \\
\text { Porto Seguro - BA, Praia do Campeche, Região, Ribeirão Preto, Santa Catarina, } \\
\text { Serra do Cipó - MG, Sul da Bahia, União Europeia. }\end{array}$ \\
\hline $\begin{array}{l}\text { Cenários do Lazer, Cidade Turística, Cluster Ecoturístico, Economia do Turismo, } \\
\text { Ecoturismo, Ecoturismo Comunitário, Esportes Radicais, Estudos de Capacidade } \\
\text { de Suporte Turístico, Impacto Turístico, Impactos do Turismo, Implantação } \\
\text { Hoteleira e Turística, Inventário Turístico, Marketing Turístico, Ocupaço } \\
\text { Turística Litorânea, Perfil dos Visitantes, Resorts, Serviços Turísticos, Sociologia } \\
\text { do Turismo, Turismo Ambiental, Turismo Brotas, Turismo de Aventura, Turismo } \\
\text { e Meio Ambiente, Turismo Sustentável, Turismo Urbano, Utilização Turística de } \\
\text { Fazendas. }\end{array}$ \\
\hline
\end{tabular}


Continuação... \begin{tabular}{|l|l|} 
Geral & $\begin{array}{l}\text { Comunicação, CTM, Educação Superior, Enraizamento, Equação Universal, } \\
\text { Hipótese Biofílica, Representações Sociais, Responsabilidade Social, Sociedade de } \\
\text { Risco, Transdisciplinaridade, Unidade, Vanguardas. }\end{array}$
\end{tabular} QUADRO 1 - AGRUPAMENTO DE TEMAS POR PALAVRAS-CHAVE ENCONTRADAS NAS TESES.

Fonte: Barbosa (2008).

A área Turismo e Meio Ambiente caracterizou-se pelo seu aspecto intermultidisciplinar demonstrado nas palavras-chave encontradas e agrupadas em temas.

\subsection{ANÁLISE DOS AUTORES}

Quando da análise dos currículos dos autores verificou-se que se graduaram entre 1968 e 1999; dos 63 trabalhos analisados, 34 foram redigidos por mulheres e 29, por homens.

Observou-se que quase metade dos pesquisadores - 27 deles - se graduou nos anos 80, seguidos daqueles que concluíram nos anos $90-17-$, nos anos $70-13-\mathrm{e}$ apenas 1 em 1968. Projetou-se um perfil de pesquisadores na faixa etária de 40 a 50 anos, já que 47 pesquisadores se formaram nas décadas de 1980 e 1990 . Ressalta-se que, da amostragem total de 63 pesquisadores, 10 currículos não estavam disponíveis no Lattes; portanto, 53 foram analisados.

Quanto ao curso de formação (graduação), os resultados encontrados indicaram uma grande variedade de cursos, destacando-se a Geografia, curso de formação de 16 doutores; seguida da Agronomia, com 8 autores formados; Turismo, Sociologia e Biologia, com 5; Engenharia, Arquitetura e Administração, com 4 formados, e, finalizando, provindos dos cursos de Serviço Social, Relações Públicas, Oceanologia, Medicina, Letras, Ciências Florestais (cursado fora do Brasil), Educação Física, Ecologia e Comunicação Social, cursos em que se formaram 1 (um) doutor cada (Figura $4)$. 


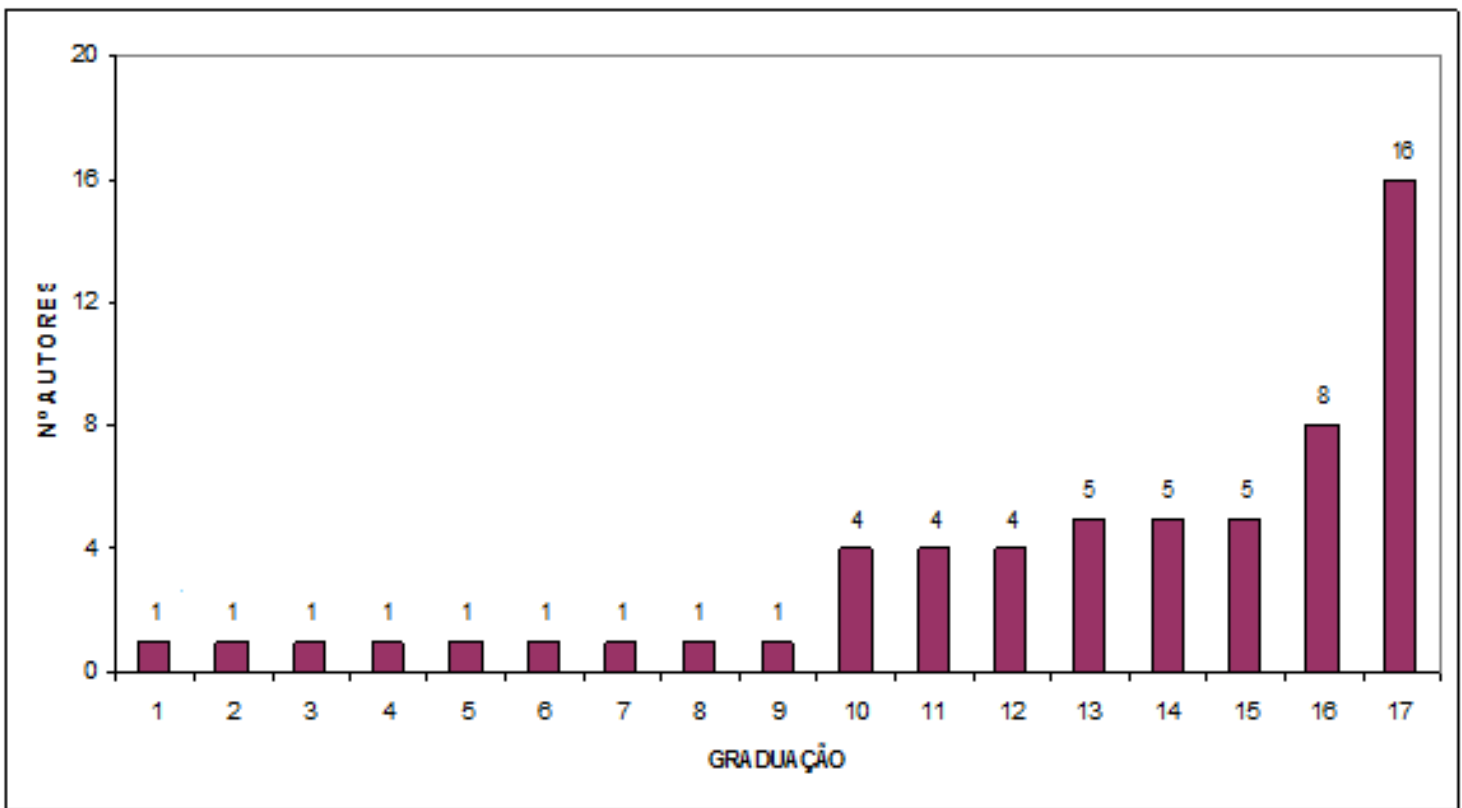

FIGURA 4 - GRÁFICO CRESCENTE REPRESENTANDO A QUANTIDADE E O PERCENTUAL DE AUTORES E SEUS CURSOS DE GRADUAÇÃO, SEGUNDO ANÁLISE DOS CURRÍCULOS DISPONÍVEIS NA PLATAFORMA LATTES.

Fonte: Pesquisa de gabinete, 2008.

\footnotetext{
Legenda:

1 = Comunicação Social

$2=$ Ecologia

3 = Educação Física

$4=$ Exterior (Ciências

Florestais)

$5=$ Letras
}

$$
\begin{aligned}
& 6=\text { Medicina } \\
& 7=\text { Oceanologia } \\
& 8=\text { Relações Públicas } \\
& 9=\text { Serviço Social } \\
& 10=\text { Administração } \\
& 11=\text { Arquitetura }
\end{aligned}
$$

$$
\begin{aligned}
& 12=\text { Engenharia } \\
& 13=\text { Biologia } \\
& 14=\text { Sociologia } \\
& 15=\text { Turismo } \\
& 16=\text { Agronomia } \\
& 17=\text { Geografia }
\end{aligned}
$$

Traçando-se um paralelo entre as áreas do conhecimento e o curso de graduação dos autores, foi observado que:

- No geral, os doutores vieram de distintas áreas de formação na graduação, refletindo na grande diversidade de áreas do conhecimento em que estavam inseridas as teses.

- Um terço das pesquisas em turismo e meio ambiente se posicionou na área da Geografia e um quarto dos pesquisadores eram geógrafos, demonstrando uma continuidade na área de formação e pesquisa desses autores e também a forte relação dessa ciência com o Turismo, pois do ponto de vista da Geografia, é possível relacionar a atividade turística com conceitos pertencentes ao saber geográfico, como: espaço, região, paisagem, lugar e território. 
- Apenas cinco doutores eram turismólogos; portanto, pesquisadores de diferentes áreas estavam trabalhando sobre turismo e suas relações com o meio ambiente.

- Ficou ressaltada a quantidade de agrônomos que pesquisavam turismo e meio ambiente; apesar de ser um dos cursos das Engenharias, essa área do conhecimento, de formação dos doutores e de programas de pós-graduação se fez presente significativamente nas pesquisas na área de estudo para esse artigo.

\subsection{ANÁLISE DOS PROCEDIMENTOS METODOLÓGICOS}

Buscou-se nesse item relatar as principais ferramentas metodológicas utilizadas pelos autores para alcançar seus objetivos. Entretanto, há de se destacar o desafio de conceber tal análise, pois, apesar das normas definidas pela Associação Brasileira de Normas Técnicas - ABNT utilizadas pelos programas e do processo minucioso de construção das etapas que regem um trabalho científico, observou-se uma grande diversidade na forma de redigir e estruturar os textos.

Por exemplo, em alguns casos, o autor optou por redigir e organizar seu texto em capítulos, como um livro; assim, cada capítulo tendo um ou mais objetivos que, por sua vez, traziam seus respectivos procedimentos metodológicos. Essa forma de redação tendo como objetivo facilitar a publicação durante o curso, pois cada capítulo da pesquisa resulta em um artigo (BARBOSA, 2008).

Esse modelo de estruturação do trabalho científico, que foge do tradicional, conforme indicações da literatura nacional sobre metodologia do trabalho científico, se deu em três teses, duas na USP/São Paulo, nos programas de Geografia e Arquitetura e Urbanismo (ambas na área de humanas), e uma na USP/São Carlos, no programa de Ciências da Engenharia Ambiental.

Em relação aos procedimentos metodológicos, em 23 trabalhos se utilizaram uma ou mais das seguintes técnicas: entrevista, observação local, pesquisa-ação, análise da realidade empírica e observação livre e participante. Esses procedimentos foram utilizados pelos autores na avaliação do ambiente em estudo, em que relataram e 
avaliaram com as suas percepções os fatos encontrados de acordo com sua experiência enquanto pesquisadores.

Como exposto na análise disciplinar, a Geografia é a área em que mais se pesquisa temas relacionados a turismo e meio ambiente, o que corrobora a quantidade de técnicas pertencentes à Geografia utilizadas nos procedimentos metodológicos analisados, como: mapeamento, análise espacial, geoprocessamento, sensoriamento remoto, cartografia, imagens de satélite, fotografias aéreas e Sistema de Informação Geográfica - SIG, que se fizeram presentes em oito teses.

O estudo de caso, como ferramenta metodológica, esteve presente em oito trabalhos.

Trabalhos com o propósito de medir e avaliar os impactos da atividade turística no meio natural, calculando a capacidade que o ambiente suporta, objetivando, portanto, seu uso sustentável, utilizaram métodos para estudo de capacidade de carga e/ou suporte (seis teses).

Identificou-se também, em quatro teses, o uso de práticas metodológicas das Ciências Econômicas, com a finalidade de valoração de atrativos, como: método de valoração pelo uso direto dos recursos naturais, método de avaliação contingente, técnicas de disposição a pagar, fluxo de caixa, gastos dos visitantes, técnica de grupos de foco para percepção sobre motivação, mensuração de experiência e satisfação com o produto turístico, entre outros.

Com foco no estudo da qualidade ambiental, especialmente recursos hídricos, os procedimentos metodológicos observados foram: análises físico-químicas e biológicas de qualidade de água e caracterização e análise do meio físico, presentes em três teses.

Metodologias específicas de planejamento e gestão aplicadas às empresas, como Planejamento Ambiental Municipal do Turismo - PLAMTUR e a técnica Delphi, também foram relatadas em duas teses.

\section{CONCLUSÃO}

No Brasil, conforme observado neste arquivo, as pesquisas científicas sobre o tema turismo e meio ambiente têm início formal em 1993 e, até o ano de 2006, o 
período de maior produção de teses se deu em 2002. Considera-se que os autores foram influenciados pelas discussões nas décadas de 70 e 80 sobre a importância da dimensão ambiental para a sustentabilidade do processo de desenvolvimento.

As Universidades no Estado de São Paulo (USP, UNESP, UNICAMP, UFSCar e FGV) produziram juntas 42 teses, se destacando entre os demais Estados.

Dentre as palavras-chave correlacionadas com a área turismo e meio ambiente, utilizadas na busca das teses no portal da CAPES, teve-se com maior incidência Ecoturismo (69\%), reforçando ser o segmento mais estudado em turismo e meio ambiente, seguido de Turismo Sustentável (13,8\%).

A faixa etária dos doutores variou de 40 a 50 anos, pois 47 pesquisadores se formaram nas décadas de 1980 e 1990, conforme consulta ao currículo dos autores na Plataforma Lattes ${ }^{7}$; assim, tendo-se um perfil de jovens pesquisadores.

Ressalta-se que no levantamento geral da pesquisa científica em turismo e meio ambiente se procurou abarcar todas as teses defendidas no Brasil até 2006, por meio dos procedimentos metodológicos definidos para tal, procurando-se evitar que, porventura, alguma pesquisa não fosse localizada.

Esclareça-se que esse inventário dos temas e autores na área de turismo e meio ambiente foi um estudo inicial de pesquisas que objetivavam analisar a produção acadêmica nessa área, portanto espera-se que esse tipo de pesquisa tenha continuidade, pois, sem dúvida, mais teses foram produzidas nos bancos dos cursos de pós-graduação espalhados pelas IES no Brasil e, consequentemente, devem ser reunidas e analisadas, para desvendar novos caminhos na relação do fenômeno do turismo com o meio ambiente.

\section{REFERÊNCIAS}

CAPES - Coordenadoria de Aperfeiçoamento de Ensino Superior. Portal de Teses e Dissertações. Disponível em: <ww.capes.gov.br/servicos/banco-de-teses>. Acesso em: dez. 2006.

\footnotetext{
${ }^{7}<$ http://lattes.cnpq.br/>.
} 
BARBOSA, S. M. Inventário dos temas e autores na área de turismo e meio ambiente. Araraquara, 2008. Dissertação (Mestrado em Desenvolvimento Regional e Meio Ambiente) - Centro Universitário de Araraquara.

DIAS, R. Turismo sustentável e meio ambiente. São Paulo: Atlas, 2003.

FERRETTI, E. R. Turismo e meio ambiente: uma abordagem integrada. São Paulo: Roca, 2002.

HALLAL, D. R. et al. O Contexto de Criação dos Cursos de Bacharelado em Turismo no Brasil. In: COLÓQUIO INTERNACIONAL SOBRE GESTION UNIVERSITÁRIA EN AMÉRICA DEL SUR, 5, 2011. Anais... Mar del Plata, 2010. v. 1, p. 1-14.

LEMOS, A. I. G. Turismo: impactos socioambientais. São Paulo: Hucitec, 2001.

MAMEDE, V. S. M. D. Participação e desenvolvimento do turismo local. In: MARTINS, C. (Organizador). Turismo, cultura e identidade. São Paulo: Roca, p. 3138, 2003.

MOMM, C. F. M.; SANTOS, R. N. M. Conhecimento científico produzido nos cursos de pós-graduação (Stricto sensu) em turismo e áreas correlatas no Brasil no período de 2000 a 2006. Revista Brasileira de Pesquisa em Turismo, v. 4, n. 2, p. 64-85, 2010.

ONU. Declaração do Rio sobre Meio Ambiente e Desenvolvimento. Disponível em: <http://www.onu.org.br/rio20/img/2012/01/rio92.pdf>. Acesso em: 17 jul. 2015.

PASSOS, P. N. C. A conferência de Estocolmo como ponto de partida para a proteção internacional do meio ambiente. Revista Diretos Fundamentais \& Democracia, v. 6, p. 1-25, 2009.

PINTO, A. C. B. Turismo e meio ambiente: aspectos jurídicos. Campinas: Papirus, 2001.

PIRES, P. S. Dimensões do ecoturismo. São Paulo: SENAC, 2002.

QUEIROZ, O. T. Atividades turísticas e recursos naturais. In: QUEIROZ, O. T. (Organizador). Turismo e ambiente: temas emergentes. Campinas: Alínea, 2006.

REJOWSKI, M. Pesquisa acadêmica em turismo no Brasil (1975 a 1992): configuração e sistematização documental. São Paulo, 1993. Tese (Doutorado em Ciências da Comunicação) - ECA/USP.

Realidade das pesquisas turísticas no Brasil: visão de pesquisadores e profissionais. São Paulo, 1995. Tese (Livre-Docência) - ECA/USP.

RODRIGUES, A. B. Ecoturismo no Brasil: possibilidades e limites. São Paulo: Contexto, 2003. 
Turismo e ambiente: reflexões e propostas. São Paulo: Hucitec, 2000.

RUSCHMANN, D. Turismo e planejamento sustentável: a proteção do meio ambiente. Campinas: Papirus, 2001.

SANTOS, M. M. C.; POSSAMAI, A. M. P.; MARINHO, M. F. Pesquisa em turismo: panorama das teses de doutorado produzidas no Brasil de 2005 a 2007. Revista Brasileira de Pesquisa em Turismo, v. 3, n. 3, p. 3-33, 2009.

SCHMIDT, M. L. S. et al. (Orgs.). Programa de pós-graduação em psicologia escolar e do desenvolvimento humano: 40 anos. São Paulo: Instituto de Psicologia, 2010.

SILVEIRA, M. A. T. Planejamento territorial e dinâmica local: bases para o turismo sustentável. In: RODRIGUES, A. B. (Organizador). Turismo desenvolvimento local. São Paulo: Hucitec, 1997.

SEQUINEL, M. C. M. Cúpula mundial sobre desenvolvimento sustentável Joanesburgo: entre o sonho e o possível. Análise Conjuntural, v. 24, n. 11-12, p. 12 15, nov./dez. 2002.

SWARBROOKE, J. Turismo Sustentável: conceitos e impacto ambiental. São Paulo: Aleph, 2000.

VILAS BOAS, M. H. A.; DIAS, R. Biodiversidade e turismo: o significado e importância das espécies-bandeira. Turismo e Sociedade, v. 3, n. 1, p. 1-24, 2010.

Recebido em: 07-07-2014.

Aprovado em: 06-08-2014. 